Elsevier required licence: (c) <2019>.

This manuscript version is made available under the CC-BY-NC-ND 4.0 license

http://creativecommons.org/licenses/by-nc-nd/4.0/

The definitive publisher version is available online at

https://www.sciencedirect.com/science/article/pii/S0959652618329809?via\%3Dihub 


\title{
Structural Transformation of Manufacturing, Natural Resource Dependence, and Carbon Emissions Reduction: Evidence of a Threshold Effect from China
}

\author{
Zhi Li ${ }^{a}$, Shuai Shao ${ }^{b}$, Xunpeng Shi e,c,d,f , Yongping Sun ${ }^{c, d}{ }^{*}{ }^{*}$, Xiaoling Zhang g,h
}

\author{
a China Center for Energy Economics Research, School of Economics, Xiamen University, \\ Xiamen, 361005, China \\ b School of Urban and Regional Science, Shanghai University of Finance and Economics, Shanghai \\ 200433, China \\ c School of Low Carbon Economics, Hubei University of Economics, China \\ ${ }^{\mathrm{d} C e n t e r}$ of Hubei Cooperative Innovation for Emissions Trading System, Hubei University of Economics, \\ Wuhan, 430205, China \\ e Australia-China Relations Institute, University of Technology Sydney, Australia \\ f Energy Studies Institute, National University of Singapore, 119620 Singapore \\ g Department of Public Policy, City University of Hong Kong, Hong Kong \\ h Shenzhen Research Institute, City University of Hong Kong, Shenzhen, China
}

Highlights:

1. The STIRPAT model and panel threshold model are employed in this paper.

2. Manufacturing structure rationalization and upgrading will help to curb carbon dioxide emissions.

3. The emissions reduction effect of structural transformation is affected by resource dependence.

4. A higher degree of industrialization can weaken the restricting effect of resource dependence.

\section{ABSTRACT}

Natural resource endowment has a significant influence on manufacturing structure which in turn influences $\mathrm{CO}_{2}$ emissions. This paper investigates the effect of the rationalization and upgrading of manufacturing structure on carbon dioxide emissions in China, based on the perspective of natural resource dependence. The results of the STIRPAT model on provincial panel data of the manufacturing sector from 2003 to 2014 show that manufacturing structure rationalization and upgrading will help curb $\mathrm{CO}_{2}$ emissions, while such effects are restricted by a region's reliance on natural resources. The panel threshold model estimations further indicate that the

\footnotetext{
${ }^{*}$ Corresponding author. Sun Yongping

E-mailing address: sunyp@hbue.edu.cn
} 
greater the ratio of industrial output to GDP, the weaker the restricting effect of resource dependence on the emissions reduction of manufacturing structure. These findings reveal that the development strategies of manufacturing structural rationalization and upgrading that aim to reduce emissions depend on the level of a region's resource dependence and industrialization.

Keywords: Manufacturing structure; natural resource dependence; $\mathrm{CO}_{2}$ emissions; threshold effect.

\section{Introduction}

A growing body of literature shows that greenhouse gas emissions pose a serious threat to human survival and the sustainable development of society and the economy. Therefore, the control and reduction of carbon dioxide emissions and the development of low-carbon economies are increasingly the focus of international attention (Mundaca and Markandya, 2016). To address the non-traditional security threats faced by climate change, China has fully integrated the control of greenhouse gas (GHG) emissions into its overall national strategy of economic and social development, taking this as a major opportunity to realize the transformation of its development mode, while simultaneously undertaking responsibility for its own international obligations. However, as the largest developing country in the world, China is still in a late stage of industrialization. Its industrial structure, energy mix, and transportation model have not yet undergone a fundamental transformation and its quality of economic growth still faces enormous challenges compared to developed countries (Sun et al., 2018). This challenging situation, however, creates a good example for developing countries to learn how to balance emissions reductions with economic development.

Huge international pressure to reduce its emissions, and the increasingly serious dual constraints of resources and the environment, have made China's transformation into a low-carbon economy an imperative need. China overtook the United States as the world's largest carbon emitter in 2009. An industrial structure weighted towards heavy industry is the main cause of China's large carbon emissions (Bithas and Kalimetris, 2016). Reducing the share of industrial added value to GDP will help to reduce the curvature of the "Kuznets" curve (Lin and Jiang, 2009). Therefore, industrial structural transformation, especially improvement in the manufacturing sectors, will help improve the efficiency of economic growth and the environment, thus reducing carbon emissions (Zhou et al., 2013; Li and Lin, 2017) and achieving China's Intended Nationally Determined Contribution (INDC) goals.

However, industrial structure is largely influenced by regional natural resource endowment (Sun and Ye, 2012). This is especially the case for regions with abundant 
resources in which resource industries are the leading pillar industries upon which other (usually resource-intensive and high-emission) industries depend. This " Single industry in an economy" is formed through the market, where all kinds of industries are competing and interacting with some spontaneity, endogeneity, and rationality in the inner economic system.

Many resource-rich countries plunged into an economic downturn at the end of the 20th century. Numerous studies have shown that the natural resources sector, with its comparative advantages, has attracted the investment of material capital and human capital, leading to the shrinking of the manufacturing sector with the effect of learning by doing and technological spillover, resulting in the extrusion effect of "deindustrialization" (Gylfason and Zoega, 2006). Shao and Yang (2014) clarified the meanings and measures of the abundance of natural resources and the dependence on natural resources, and found that abundant natural resources themselves usually have a positive effect on economic growth, but regions with abundant resources find it easier to embark on the path of resource-dependent development, and over-reliance on resources is the source of "resource curse". ${ }^{1}$ Sun and Ye (2012) further point out that resource dependence in resource-rich regions can hinder the diversification of industries and affect the advancement of their industrial structure. Facing a background of continually increasing global low-carbon competition, resource-based regions need to promote the diversified development of industries by policies and external forces and remove the high-carbon lock-in effect and incentivize green lowcarbon development. However, it is very difficult to develop alternative low-carbon industries and change the industrial structure to reduce emissions.

Empirical findings also suggest that there are great differences in the direction and speed of industrial restructuring in resource abundant countries during different stages of economic development. Success stories in countries such as Australia, Chile, and Norway show that the "resource curse" is not a universal law. The transformation of industrial structure is affected by many factors such as GNP per capita, technology, etc (Baldwin et al., 2005, Chang, 2015). Along with the economic development, the leading industry (especially a leading manufacturing industry) tends to gradually transform from labor- to capital-intensive, and then to technology-intensive; energy efficiency has different trends in different stages of industrialization, which means that the "structural emissions reduction" effect is also very different (Sharma, 2011;Liu and Xie, 2013). In addition, resource-based regions can use mineral resources to promote the development of high-tech industries and thus have an important effect on the

\footnotetext{
${ }^{1}$ The resource curse, also known as the paradox of plenty, refers to the paradox that countries with an abundance of natural resources (like fossil fuels and certain minerals), tend to have less economic growth, and worse development outcomes than countries with fewer natural resources (Auty and Warhurst, 1993).
} 
economy. However, the resource industry may have a nonlinear threshold effect on technological advancement and economic development. After the expansion of the scale of the resource industry to a certain level, the original "resource gospel" could shift toward a "resource curse" (Ma and Cheng, 2017).

The above reviews suggest that the industrial structure of an economy is inextricably linked with a dependence on resources, and the emissions reduction effect of structural transformation is affected by the degree of dependence involved; moreover, the relationship may present different evolutionary trends and characteristics at different levels of economic development. However, there have been few studies to address these issues to date. Considering the richness of the connotation of industrial structure, most studies and practical decisions tend to be focused on optimization in one dimension of industrial structure without revealing the complexity of industrial transformation (Fu et al., 2016). Further study is important for developing countries that face industrial transformation, such as China. China is in a mid- and post-industrialization stage, and industrial growth is still the main driving force of its economic development. China's industrial transformation therefore focuses on industry, especially the manufacturing industry.

The purpose of this paper is to reveal the complexity of industrial transformation with consideration to resource dependency and emissions reduction. Both industrial structure rationalization, and upgrading are examined, and the non-linear effect of economic development is considered. The contributions of this paper are threefold. First, we describe the emissions reduction effect of structural transformation from rationalization and upgrading perspectives, and construct corresponding indices. Second, we investigate the impact of resource dependence on the emissions reduction effect of structural transformation. An academic contribution is the introduction of the rationalization and upgrading of manufacturing industries as proxy variables for technology in the STIRPAT model. Third, we introduce a panel threshold model to estimate these effects based on the subpanels, considering the heterogeneity of industrialization stages.

The paper is organized as follows: Section 2 discusses the relationship between manufacturing structure transformation and carbon dioxide emissions, puts forward the relevant hypotheses, and constructs the STIRPAT and panel threshold model. Section 3 details the data and measuring indexes of rationalization and upgrading of manufacturing industries. Section 4 describes the empirical results. Section 5 concludes the paper with policy implications. 


\section{Hypothesis and model specification}

\subsection{Influence mechanism of manufacturing structure on emissions}

According to the literature, manufacturing structural transformation can be characterized as the rationalization and upgrading of structure (Fu et al., 2016). Rationalization reflects the degree of coordination between manufacturing industries, especially the efficiency of resource allocation among manufacturing industries. A rational manufacturing structure with optimal resource allocation will help reduce energy consumption and carbon dioxide emissions. Upgrading of manufacturing structure refers to the transition from second category industries such as petrochemical, steel, non-ferrous metals, and other heavy chemical industries to third category industries such as machinery and equipment and other high-end manufacturing industries with high value-added, low energy consumption, and carbon emissions (Fu et al., 2016; Li and Lin, 2017). The shift will restrain the further expansion of the high-energy-consumption industries and decrease the speed of growth of carbon emissions. Based on the above, we propose hypothesis 1: Improving manufacturing structure rationalization and upgrading can help reduce carbon dioxide emissions.

Resource endowment is an important factor that determines the initial layout of regional industries (Sun and Ye, 2012). Regions with abundant natural resources tend to give priority to the development of resource-based industries. Abundant natural resources usually have a positive effect on economic growth. However, when the economy relies too heavily on natural resources, both human and physical capital are locked into resource industries, and "resource curse" is prone to occur due to the crowding-out effect, which will distort the rationalization and upgrading of manufacturing industries and further weaken the "structural bonus" of emissions reduction. Therefore, we propose hypothesis 2: More dependence on natural resources will further weaken the emissions reduction effect of the structural transformation in manufacturing.

The structural transformation is affected by such factors as the level of economic development (Li and Lin, 2017). At different stages of economic development, there may exist different dominant characteristics in the manufacturing structure and the effects of the dependence on resources on manufacturing industries may also be different, further increasing the differences in the emissions reduction effect of structural transformation. Therefore, we propose hypothesis 3: The effects of structural transformation in manufacturing on $\mathrm{CO}_{2}$ emissions vary among different stages of economic development. 
This paper establishes econometric models based on a series of test methods and model estimations to test the above three hypotheses.

\subsection{Model specification}

In the literature, the IPAT equation (holds that environmental impact (I) is the product of three factors: population (P), affluence (A) and technology (T) ), proposed by Ehrlich and Holdren (1971) is often used to quantify the effects of technology, population, and the economy on the natural environment. However, since the IPAT equation provides only monotonically and proportionally changing relations, it fails to measure the different effects of various factors on the environment (Zhang and Lin, 2012). To overcome such limitations, York et al. (2003) propose a more flexible model, the STIRPAT model, given by the stochastic form:

$$
I=a P^{b} \times A^{c} \times T^{d} e
$$

where $I, P, A$, and $T$ represent the environmental impact, population size, affluence, and technological progress respectively; $a, b, c$, and $d$ are the parameters to be estimated; and $e$ is a random disturbance factor. After taking the natural logarithm form, the above equation becomes

$$
\ln I=\ln a+b \ln P+c \ln A+d \ln T+\ln e
$$

Compared to IPAT, the STIRPAT ( (STochastic Impacts by Regression on Population, Affluence and Technology) model not only allows each coefficient to be estimated as an unknown parameter, but also allows various factors to be appropriately improved or decomposed.

Previous work often makes improvements based on (2) in order to carry out empirical studies ( Poumanyvong and Kaneko, 2010; Liddle, 2013). In these empirical studies, $I$ is measured by $\mathrm{CO}_{2}$ emissions, denoted by $\mathrm{CO}_{2}, P$ represents the total population, denoted by Pop, and $A$ is measured by GDP per capita. For $T$, Bongaarts(1992) argues that different levels of technology can be mapped by different economic structures. Therefore, Poumanyvong and Kaneko (2010) and Zhang and Lin (2012) use the GDP share of industry and service as proxy variables for technology $T$. Martínez-Zarzoso et al. (2007) and Martínez-Zarzoso and Maruotti (2011) use the GDP share of industry and energy intensity.

An innovation of the current study is to use specially constructed indicators $T R$ and $\mathrm{TH}$, which measure the rationalization and upgrading of manufacturing industries, respectively, as proxy variables for technology $T$, in order to investigate the impact of manufacturing structural transformation on $\mathrm{CO}_{2}$ emissions ( $\mathrm{Li}$ and $\mathrm{Lin}, 2017$ ).

Therefore, the benchmark model based on panel data is derived as 


$$
\ln C O_{2 i t}=\alpha_{0}+\alpha_{1} \ln P o p_{i t}+\alpha_{2} \ln G d p_{i t}+\alpha_{3} \ln T R_{i t}+\alpha_{4} \ln T H_{i t}+e_{i t}
$$

From the Hypothesis 2, dependence on resources is an important factor determining the initial layout of the industries in a region, and the effect of structural changes in manufacturing industries on $\mathrm{CO}_{2}$ emissions in different regions may be constrained by the region's natural resource endowment. Therefore, it is necessary to introduce "dependence on resources" (R), which is measured by the percentage of mining industry employees of the whole industrial sector (Sun and Ye, 2012), into the model as cross-terms to capture its impact.

$$
\begin{aligned}
& \ln C O_{2 i t}=a_{0}+a_{1} \ln P o p_{i t}+a_{2} \ln G d p_{i t}+a_{3} \ln T R_{i t}+a_{4} \ln T H_{i t}+\alpha_{5} R \times \ln T R_{i t}+e_{i t} \\
& \ln C O_{2 i t}=b_{0}+b_{1} \ln P o p_{i t}+b_{2} \ln G d p_{i t}+b_{3} \ln T R_{i t}+b_{4} \ln T H_{i t}+b_{6} R \times \ln T H_{i t}+u_{i t}
\end{aligned}
$$

According to Hypothesis 3 , the emissions reduction effect of structural transformation in manufacturing under resource constraints varies between different stages of economic development. Therefore, we measure the level of economic development (denoted as $g$ ) by the ratio of industrial output to GDP as threshold variables, expanding (4) and (5) using Hansen's (1999) panel threshold model. Differing from the regression model with a grouped exogenous sample, the threshold model estimates the endogenous threshold parameters and other parameters of each group just once, which significantly improves the accuracy of the estimation and allows the research object to shift between different groups over time, with threshold variables over the sample period. The specific form is

$$
\begin{aligned}
\ln C O_{2 i t}= & c_{0}+c_{1} \ln P o p_{i t}+c_{2} \ln G d p_{i t}+c_{3} \ln T R_{i t}+c_{4} \ln T H_{i t} \\
& +c_{5}\left(R \times \ln T R_{i t}\right) I(g \leq \gamma)+c_{6}\left(R \times \ln T R_{i t}\right) I(g>\gamma)+m_{i t} \\
\ln C O_{2 i t}= & d_{0}+d_{1} \ln P o p_{i t}+d_{2} \ln G d p_{i t}+d_{3} \ln T R_{i t}+d_{4} \ln T H_{i t} \\
& +d_{5}\left(R \times \ln T H_{i t}\right) I\left(g \leq \gamma^{\prime}\right)+d_{6}\left(R \times \ln T H_{i t}\right) I\left(g>\gamma^{\prime}\right)+n_{i t}
\end{aligned}
$$

where $I(\cdot)$ is the indicator function, which shows the regime defined by threshold variable $g$ and the threshold value $\gamma$ or $\gamma^{\prime}$ to be estimated. When the conditions in parentheses are satisfied, the value is 1 , otherwise it is 0 . Eqs. (6) and (7) can respectively measure the different effects of the rationalization and upgrading of the manufacturing structure on $\mathrm{CO}_{2}$ emissions due to the different levels of economic development, which are constrained by natural resources. In other words, it depicts the emissions reduction effect of structural transformation in different regions under resource constraints because of nonlinear conversion characteristics due to a certain value (threshold) of the level of economic development. In addition, unlike the traditional Chow tests, Eqs. (4) and (5) identify the threshold endogenously based on the characteristics of the data of economic operations, thus avoiding subjectively false setting the model. 
The above model assumes that there is only one threshold; i.e., the effect of each variable on $\mathrm{CO}_{2}$ emissions is divided into two mechanisms due to the different threshold values. However, there may appear multiple thresholds. Assuming $\gamma_{1}<\gamma_{2}$, $\gamma_{1}^{\prime}<\gamma_{2}^{\prime}$ and taking the double-threshold (three-mechanism) model as an example, the models are modified to

$$
\begin{aligned}
\ln C O_{2 i t}= & f_{0}+f_{1} \ln P o p_{i t}+f_{2} \ln G d p_{i t}+f_{3} \ln T R_{i t}+f_{4} \ln T H_{i t}+f_{5}\left(R \times \ln T R_{i t}\right) I\left(g \leq \gamma_{1}\right) \\
& +f_{6}\left(R \times \ln T R_{i t}\right) I\left(\gamma_{1}<g \leq \gamma_{2}\right)+f_{7}\left(R \times \ln T R_{i t}\right) I\left(g>\gamma_{2}\right)+v_{i t} \\
\ln C O_{2 i t}= & h_{0}+h_{1} \ln P o p_{i t}+h_{2} \ln G d p_{i t}+h_{3} \ln T R_{i t}+h_{4} \ln T H_{i t}+h_{5}\left(R \times \ln T H_{i t}\right) I\left(g \leq \gamma_{1}^{\prime}\right) \\
& +h_{6}\left(R \times \ln T H_{i t}\right) I\left(\gamma_{1}^{\prime}<g \leq \gamma_{2}^{\prime}\right)+h_{7}\left(R \times \ln T H_{i t}\right) I\left(g>\gamma_{2}^{\prime}\right)+w_{i t}
\end{aligned}
$$

\section{Variables and data}

\subsection{Structural transformation in the manufacturing sector}

There are two dimensions measuring industrial structural changes in the rationalization and upgrading of industrial structure (Gan et al., 2011). The Chinese structural adjustment is mainly made in the manufacturing sectors. Based on the existing literature, we introduce two measurement indices reflecting the three manufacturing categories, ${ }^{2}$ in order to measure the structural transformation (Fu et al., 2016; Li and Lin, 2017).

\subsubsection{Manufacturing structure rationalization}

Gan et al. (2011) hold that industrial structure rationalization (denoted as TR) can be measured by the Theil index of industrial structure, and Fu et al.(2016) apply it to the three categories of the manufacturing industry by

\footnotetext{
${ }^{2}$ Fu et al. (2016) claimed that the first category (that is low-end) comprised the food, leather, beverage, wood, tobacco, textile, furniture, paper, printing, and culture manufacturing sectors; the second category (mid-end) comprised the petroleum, raw chemical material, medicine, chemical fiber, rubber, plastic, non-metal, and metal manufacturing sectors; and the third category (high-end) comprised the machinery, transport equipment, communication equipment, electrical machinery and equipment, and measuring instrument manufacturing sectors.
} 


$$
T R=\sum_{i=1}^{n}\left(\frac{Y_{i}}{Y}\right) \ln \left(\frac{Y_{i}}{L_{i}} / \frac{Y}{L}\right)=\sum_{i=1}^{n}\left(\frac{Y_{i}}{Y}\right) \ln \left(\frac{Y_{i}}{Y} / \frac{L_{i}}{L}\right)
$$

where variables $Y$ and $L$ denote the total output and employment of the manufacturing industry respectively, $Y_{i}$ and $L_{i}$ are the output and employment respectively of category $i$ of the manufacturing industry. $R / L$ is labor productivity. If labor can move freely, the marginal output of labor in each category of manufacturing is the same, that is, the same labor productivity, which means that the output structure, $Y_{i} / Y$, and employment structure, $L_{i} / L$, of manufacturing are consistent, and the value of $T R$ is 0 . In that case, the manufacturing structure is in a balanced state, which means that resources are optimally allocated among the manufacturing industries, and the manufacturing structure is reasonable. However, due to the limitation of resources or asset specificity and the degree of marketization, manufacturing labor productivity cannot be the same across industries; therefore, the structure of output and employment cannot be consistent. Finally, it is normal for the economy to deviate from equilibrium, especially in developing countries (Chenery and Srinivasan, 1989; Ma and Cheng, 2017). In order to describe the consistency, we take the reciprocal of the index as a measure of manufacturing structure rationalization; that is, the greater the value, the more rational the manufacturing structure.

\subsubsection{Upgrading manufacturing structure}

According to the existing literature, as the industrialization process advances, the manufacturing industry gradually transfers to the third category, i.e., high-end manufacturing (Fu et al., 2016; Li and Lin, 2017). We use the ratio of employment in the third category of manufacturing to the employment in the second category as a measure of manufacturing structure upgrading (denoted as $T U$ ). The greater the value of TU, the more advanced the manufacturing. That is, the transfer from the petrochemical, non-ferrous, and other heavy chemical industry-based second category to the machinery and equipment and other high-end manufacturing industry-based third category. This measure can clearly reflect manufacturing upgrading which helps curb the further expansion of high-energy-consuming industries, reduce the growth in carbon emissions, and promote emissions reduction.

\subsection{Measurement of dependence on natural resources}

The structural transformation of manufacturing is constrained by a region's dependence on resources, which is mainly reflected by the dependence of resourcebased industries. Appropriate indicators commonly include the proportion of mining 
output, investment, employment, or the proportion of primary products exported to the total output. In the present paper, we adopt the percentage of mining industry employees in the whole industrial sector to measure the degree of each region's resource dependence. According to the current industry classification in China, the mining industry includes coal mining and washing, oil and natural gas extraction, ferrous metal mining, non-ferrous metal mining and dressing, non-metallic ore mining and dressing, and other mining industries, covering all primary industries related to natural resources. Therefore, the above indicators can fully reflect the dependence of a city on local resources from an employment perspective (Shao and Yang, 2014).

\subsection{Control variables and threshold variables}

(1) According to the STIRPAT model, the total population (denoted by Pop) and GDP per capita (denoted by GDP) in all regions, after taking the logarithms, are introduced into the model as the control variables.

(2) The ratio of industrial output to each region's GDP is used as a threshold variable (denoted by $g$ ) to measure the different stages of economic development in all regions.

\subsection{Per capita carbon emissions}

To calculate the total amount of carbon emissions of each region, the reference method proposed by the Intergovernmental Panel on Climate Change (IPCC) in 2006 is used. This involves data for the final energy consumption of coal, diesel, natural gas, kerosene, fuel oil, crude oil, and coke in all regions.(Mi et al., 2015). Each region's total amount of carbon dioxide emissions is divided by the total number of people to give the carbon emissions per capita.

The panel data covering 30 China provinces from 2003 to 2014 is extracted from the China Statistical Yearbook, China Industrial Statistical Yearbook, and China Economic Information Centre (CEIC) database.

\section{Results and discussion}

\subsection{Basic panel model}

According to Eqs. (3)-(5), the basic panel models 1 to 3 are firstly established to investigate the impact of the manufacturing structure on carbon dioxide emissions. The results of the Hausman test support the use of a random effect panel regression model. The estimation results are shown in Table 1. 
Table 1

Regression results for the basic panel model.

\begin{tabular}{cccc}
\hline $\begin{array}{c}\text { Explanatory } \\
\text { Variables }\end{array}$ & Model 1 & Model 2 & Model 3 \\
\hline $\ln P o p_{i t}$ & $0.6061^{* * *}(0.0915)$ & $0.7255^{* * *}(0.0691)$ & $0.6655^{* * *}(0.0813)$ \\
$\ln G d p_{i t}$ & $0.5739^{* * *}(0.0203)$ & $0.5541^{* * *}(0.0214)$ & $0.5703^{* * *}(0.0229)$ \\
$\ln T R_{i t}$ & $-0.0118^{*}(0.009)$ & $-0.0234^{*}(0.0125)$ & $-0.0724^{*}(0.0109)$ \\
$\ln T U_{i t}$ & $-0.1654^{* * *}(0.0082)$ & $-0.1796^{* * *}(0.0351)$ & $-0.1997^{* * *}(0.0412)$ \\
$R \times \ln T R_{i t}$ & & $0.0029^{*}(0.0016)$ & \\
$R \times \ln T U_{i t}$ & & & $0.0097^{*}(0.0087)$ \\
$\mathrm{N}$ & 360 & 360 & 360 \\
\hline
\end{tabular}

Notes: Standard errors are shown in parentheses; * **, and $* * *$ denote $\mathrm{p}<0.1, \mathrm{p}<0.05$, and $p<0.01$, respectively

The results in model 1 show that population and GDP have a significant promoting effect on carbon dioxide emissions, and that the rationalization and upgrading of the manufacturing structure can help to realize the emissions reduction. While the "dependence on resources" is introduced into models 2 and 3 as the cross-terms, the coefficients are 0.0029 and 0.0097 respectively, indicating that the above-mentioned emissions reduction effects of structure are affected by resource dependency. The more the degree of dependence, the weaker the effect of structural emissionreduction, and thus Hypotheses 1 and 2 are supported.

\subsection{Panel threshold model}

Based on the above analysis, it is concluded that the degree of resource dependence has a restraining effect on structural emissions reduction. In this section, we introduce the panel threshold model to further investigate whether there is any non-linear effect of resource dependence on the reduction of manufacturing structure due to differing economic development levels.

Before building the threshold model, the significance of the threshold effect is tested using likelihood ratio (LR) statistics, i.e., to test whether the level of economic development has a threshold on the reduction emissions effect of structural transformation. If such a non-linear threshold effect exists, the number of thresholds should be further determined according to the sequential principle of whether the model has a dual mechanism, then a triple mechanism, etc.

For the significance test, the null hypothesis of the model taking Eq. (6) for example is $H_{0}$ : No threshold $\left(\alpha_{5}=\alpha_{6}\right)$, while the alternative hypothesis is $H_{a}$ : Single threshold $\left(\alpha_{5} \neq \alpha_{6}\right)$. Then we use Hansen's (1999) LR test statistic to test the threshold effect in the non-dynamic panel, with 


$$
L R=\left(S_{0}-S_{1}(\hat{\gamma})\right) / \hat{\sigma}^{2}
$$

where $S_{0}$ is the residual sum of squares constrained by the null hypothesis, while $S_{1}\left(\hat{\gamma}_{1}\right)$ is unconstrained, meaning the residual sum of squares at threshold value $\hat{\gamma}_{1}$. $\hat{\sigma}^{2}$ is the residual variance. Since the gradual distribution of the LR test statistic in Eq. (11) depends on the sample moments and does not obey the standard $\chi^{2}$ distribution, there is no table of critical values for reference. However, as Hansen (1999) points out, it is possible to simulate the asymptotic distribution with large samples using such methods as bootstrapping, and then construct the threshold of the LR test to see whether there is a significant threshold effect. Following Hansen's practice, therefore, this paper searches only for non-repetitive values of the threshold variable while the threshold ranges are sought by grid searching, taking 0.05 as the bootstrap standard.

Following the sequential testing approach, after the first threshold value is tested and supposed to be $\hat{\gamma}_{1}$, the second is tested by the same method of grilling and searching and is supposed to be $\hat{\gamma}_{2}\left(\hat{\gamma}_{2}<\hat{\gamma}_{1}\right)$. The corresponding residual sum of squares is $S_{1}\left(\hat{\gamma}_{1}\right)$ and $S_{2}\left(\hat{\gamma}_{2}\right)$, and the test statistic is constructed to test such a threshold effect as: HO: Single threshold; Ha: Double thresholds, where

$$
L R_{2}(m)=\left(S_{1}\left(\hat{\gamma}_{1}\right)-S_{2}\left(\hat{\gamma}_{2}\right)\right) / \hat{\sigma}_{2}^{2}
$$

$H_{0}$ being rejected means that two thresholds are searched and, on this basis, a third or more thresholds are sequentially searched until $H_{0}$ is accepted, thereby affirming the number of thresholds. The result is usually obtained by STATA 14 software programming.

\subsubsection{Panel threshold model for structure rationalization}

The test results of the panel threshold model for manufacturing structure rationalization are shown in Table 2 . This shows that the entire sample should be divided into four subpanels for three thresholds (to be estimated) at the $5 \%$ significance level, which confirms that the panel threshold regression models are suitable. The estimated threshold values are $30.03 \%, 34.21 \%$, and $36.65 \%$ respectively, all of which are significant at the $1 \%$ significance level (see Table 3 ).

\section{Table 2}

Test results for threshold effects of manufacturing structure rationalization

Hypothesis LR




\begin{tabular}{ll}
\hline $\mathrm{H}_{0}$ : No threshold; $\mathrm{H}_{\mathrm{a}}$ : Single threshold & $24.3335^{* * *}[0.000](8.9491,4.0191$, \\
& $2.6890)$ \\
& $8.7276^{* * *}[0.0070](8.3222,3.3286$, \\
& $2.0066)$ \\
$\mathrm{H}_{0}$ : Single threshold; $\mathrm{H}_{\mathrm{a}}$ : Double threshold & $5.7378^{* *}[0.0220](7.7319,4.04,2.72)$ \\
$\mathrm{H}_{0}$ : Double threshold; $\mathrm{H}_{\mathrm{a}}$ : Triple threshold & No convergence \\
$\mathrm{H}_{0}$ : Triple threshold; $\mathrm{H}_{\mathrm{a}}$ : Quadruple threshold
\end{tabular}

Notes: 1) The critical value is based on the bootstrap method, in which the number of iterations is $1000 ; 2)$ the $p$-values are shown in square brackets, and the critical value of $1 \%, 5 \%$, and $10 \%$ are shown in parentheses; 3$)^{*}, * *, * * *$ denote $p<0.1, p<0.05$, and $p<0.01$, respectively.

Table 3

Estimation results for the threshold values of manufacturing structure rationalization

\begin{tabular}{clc}
\hline Threshold variables & Values & 95\% confidence interval \\
\hline$\hat{\gamma}_{1}$ & $30.03 \%^{* * *}$ & $(29.88,31.81)$ \\
$\hat{\gamma}_{2}$ & $34.21 \%^{* * *}$ & $(33.47,34.29)$ \\
$\hat{\gamma}_{3}$ & $36.65 \%^{* * *}$ & $(32.08,50.63)$ \\
\hline
\end{tabular}

Notes: $*, * *$, and $* * *$ denote $\mathrm{p}<0.1, \mathrm{p}<0.05$, and $\mathrm{p}<0.01$, respectively.

According to the results in Table 3, the triple-threshold (four-mechanism) model is built as follows:

$$
\begin{aligned}
\ln C O_{2 i t} & =f_{0}+f_{1} \ln P o p_{i t}+f_{2} \ln G d p_{i t}+f_{3} \ln T R_{i t}+f_{4} \ln T H_{i t}+f_{5}\left(R \times \ln T R_{i t}\right) I(g \leq 30.03 \%) \\
& +f_{6}\left(R \times \ln T R_{i t}\right) I(30.03 \%<g \leq 34.21 \%)+f_{7}\left(R \times \ln T R_{i t}\right) I(34.21 \%<g \leq 36.65 \%) \\
& +f_{8}\left(R \times \ln T R_{i t}\right) I(g>36.65 \%)+v_{i t}
\end{aligned}
$$

Table 4 provides the estimation results for Eq. (13), which indicate the effects on the emissions reduction of structural transformation caused by resource dependence, vary greatly across different levels of industrialization. As the proportion of industrial output to GDP is less than $30.03 \%$, the coefficient of the cross-term is -0.0269 , indicating resource dependence will help manufacturing structure rationalization to cut emissions. The beneficial effect begins to decrease when the proportion is between $30.03 \%$ and $34.41 \%$ and the coefficient is -0.0053 . However, dependence on resources even acts as a disincentive to reducing emissions resulting from manufacturing structure rationalization when the proportion is between $34.41 \%$ and $36.65 \%$, when the coefficient is 0.0035 . The effect is not statistically significant when the proportion is above $36.65 \%$.

\section{Table 4}

Regression results for the threshold models for manufacturing structure rationalization 


\begin{tabular}{|c|c|c|c|}
\hline $\begin{array}{c}\text { Explanatory } \\
\text { Variables }\end{array}$ & Coefficients & $\begin{array}{c}\text { Explanatory } \\
\text { Variables }\end{array}$ & Coefficients \\
\hline $\ln P o p_{i t}$ & $\begin{array}{c}0.0740 \\
(0.1487)\end{array}$ & $\left(R \times \ln T R_{i t}\right) \cdot I(g \leq 30.03 \%)$ & $\begin{array}{c}-0.0269^{* * *} \\
(0.0075)\end{array}$ \\
\hline $\ln G d p_{i t}$ & $\begin{array}{l}0.5943^{* * *} \\
(0.0208)\end{array}$ & $\left(R \times \ln T R_{i t}\right) \cdot I(30.03 \%<g \leq 34.41 \%)$ & $\begin{array}{c}-0.0053^{* * *} \\
(0.0019)\end{array}$ \\
\hline $\ln T R_{i t}$ & $\begin{array}{l}-0.0139 \\
(0.0114)\end{array}$ & $\left(R \times \ln T R_{i t}\right) \cdot I(34.41 \%<g \leq 36.65 \%)$ & $\begin{array}{l}0.0035^{*} \\
(0.0022)\end{array}$ \\
\hline $\ln T U_{i t}$ & $\begin{array}{c}-0.1314^{* * *} \\
(0.0318)\end{array}$ & $\left(R \times \ln T R_{i t}\right) \cdot I(g>36.65 \%)$ & , \\
\hline
\end{tabular}

Notes: Standard errors are shown in parentheses; ${ }^{*}, * *$, and ${ }^{* * *}$ denote $\mathrm{p}<0.1, \mathrm{p}<0.05$, and $\mathrm{p}<0.01$ respectively.

\subsubsection{Panel threshold model for structural upgrading}

Table 5 shows the test results of the panel threshold model for upgrading manufacturing structure. This shows that there are also three thresholds, thus indicating a non-linear effect. The three threshold values are $30.09 \%, 34.22 \%$, and $47.31 \%$, respectively, and all are significant at the $1 \%$ level (see Table 6 ).

\section{Table 5}

Test results for the threshold effects of manufacturing structure upgrading

\begin{tabular}{ll}
\hline \multicolumn{1}{c}{ Hypothesis } & \multicolumn{1}{c}{ LR } \\
\hline $\mathrm{H}_{0}$ : No threshold; $\mathrm{H}_{\mathrm{a}}$ : Single threshold & $17.5311^{* * *}[0.0010](6.735,3.2877$, \\
& $2.2761)$ \\
$\mathrm{H}_{0}$ : Single threshold; $\mathrm{H}_{\mathrm{a}}$ : Double threshold & $7.7899^{* * *}[0.0130](8.4394 .2581,2.6873)$ \\
$\mathrm{H}_{0}$ : Double threshold; $\mathrm{H}_{\mathrm{a}}$ : Triple threshold & $6.5878^{* * *}[0.0220](9.0176,4.0725,2.5919)$ \\
$\mathrm{H}_{0}$ : Triple threshold; $\mathrm{H}_{\mathrm{a}}$ : Quadruple threshold & No convergence
\end{tabular}

Notes: 1) The critical value is based on the bootstrap method, in which the number of iterations is $1000 ; 2)$ the $p$-values are shown in square brackets, and the critical value of $1 \%, 5 \%$, and $10 \%$ are shown in parentheses; 3$) *, * *, * * *$ denote $\mathrm{p}<0.1, \mathrm{p}<0.05$, and $\mathrm{p}<0.01$ respectively.

\section{Table 6}

Estimation results of the threshold values of manufacturing structure upgrading

\begin{tabular}{ccc}
\hline Threshold variables & Values & Confidence interval of $95 \%$ \\
\hline$\hat{\gamma}_{1}$ & $30.09 \%^{* * *}$ & $(29.88,31.81)$ \\
$\hat{\gamma}_{2}$ & $34.22 \%^{* * *}$ & $(32.72,35.37)$ \\
$\hat{\gamma}_{3}$ & $47.31 \%^{* * *}$ & $(32.33,50.63)$ \\
\hline Notes: ${ }^{*}, * *$, and ${ }^{* * *}$ denote $\mathrm{p}<0.1, \mathrm{p}<0.05$, and $\mathrm{p}<0.01$ respectively.
\end{tabular}


Similarly, the panel threshold model for manufacturing structure upgrading is built (see Table 7), indicating that the upgrading reliance on resources has varying effects on emissions reduction across industrialization stages. When the proportion of industrial output to GDP is less than $30.09 \%$, resources are helpful in upgrading manufacturing structure to reduce emissions. The emissions reduction effects decline over the next two stages, corresponding to proportions of $(30.09 \%, 34.22 \%)$ and $(34.42 \%, 47.31 \%)$. At over $47.31 \%$, the dependence on resources on the emissions reduction of structural upgrading is not significant.

Table 7

Regression results for the threshold models for manufacturing structure upgrading

\begin{tabular}{cccc}
\hline $\begin{array}{c}\text { Explanatory } \\
\text { Variables }\end{array}$ & Coefficients & $\begin{array}{c}\text { Explanatory } \\
\text { Variables }\end{array}$ & Coefficients \\
\cline { 1 - 2 } $\ln P o p_{i t}$ & 0.1927 & $\left(R \times \ln T U_{i t}\right) \cdot I(g \leq 30.09 \%)$ & $-0.1365^{* * *}$ \\
$\ln G d p_{i t}$ & $0.59^{* * *}$ & $\left(R \times \ln T U_{i t}\right) \cdot I(30.09 \%<g \leq 34.22 \%)$ & $-0.04 * * *$ \\
& $(0.0758)$ & $\left(R \times \ln T U_{i t}\right) \cdot I(34.22 \%<g \leq 47.31 \%)$ & $-0.0105^{*}$ \\
$\ln T R_{i t}$ & $-0.016^{*}$ & & $(0.0316)$ \\
& $(0.009)$ & & 0.0051 \\
$\ln T U_{i t}$ & $-0.085^{* *}$ & $\left(R \times \ln T U_{i t}\right) \cdot I(g>47.31 \%)$ & $(0.0063)$ \\
\hline
\end{tabular}

Notes: Standard errors are shown in parentheses; ${ }^{*}, * *$, and $* * *$ denote $p<0.1, p<0.05$, and $p<0.01$ respectively.

\section{Conclusion and policy implications}

Many studies in recent years investigate the impact of structural transformation on $\mathrm{CO}_{2}$ emissions. However, a region's reliance on resources may also have different effects on its $\mathrm{CO}_{2}$ emissions and can have a nonlinear trend depending on the stage of development. Thus far, little attention has been paid to this issue.

This article measures China's manufacturing industry structure rationalization and upgrading in the three manufacturing categories, and then analyzes the impacts that manufacturing structural transformation in different stages of economic development have on carbon emissions. Hansen's (1999) threshold regression model is further introduced and is expanded to the panel data to verify that the emissions reduction effect of structural transformation which is restricted by a region's reliance on natural resources is based on the non-linear characteristics of industrialization proportion level. 
The analysis of panel data covering 30 Chinese provinces from 2003 to 2014 provides the following empirical conclusions. (1) A high degree of coordination among manufacturing industries shifts them towards more high-end technology-based industries, which helps reduce carbon dioxide emissions. (2) The structural transformation in manufacturing is closely linked with the degree of resource dependence, and a high natural resource dependence restrains the emissions reduction effect of manufacturing structural transformation. Therefore, when other elements remain the same, regions with less dependence on resources are likely to achieve emission reductions by manufacturing structure rationalization and upgrading. (3) The results of the threshold model indicate that the effects vary according to the stage of industrialization development. As the proportion of industrial output to GDP improves, being subject to resource dependence, manufacturing structure rationalization, and upgrading makes less contributions to emission reductions. This may explain why the resource curse did not occur in some countries, such as Australia.

The development of resource-intensive industries in resource-based regions has its own rationality. Therefore, the priority of sustainable development in resourcebased regions is to diversify and rationalize the industrial structure rather than slow down natural resource development. These findings suggest that the government needs to implement policies in a more precise manner according to resource dependence and the stage of economic development. Specially, considering the restraining effect of resource dependence, governments, especially those in resourcebased regions, need to avoid resource dependence through the diversification structure and upgrading of manufacturing, rather than slowing down the development of the natural resources industries themselves. Since the impediment of resource dependency on the emissions reduction effect of industrial structure is only present in the early stage of industrialization, resource-based regions should promote the upgrading of resource-intensive manufacturing to one that is more technologyintensive as early as possible, thereby improving the efficiency of resource utilization and reducing carbon emissions. At the same time, it is also important to reduce carbon dioxide emissions by diversifying industrial structure and reducing excessive dependence on resource-intensive manufacturing. As industrialization levels rise, policy makers should pay more attention to weakening the reliance of manufacturing sectors on the resources.

The current study with provincial data has a limitation in that within one province, the distribution of natural resources in the geographical space is extremely uneven. Therefore, the impacts of resource dependence on carbon emissions needs to be further decomposed geographically so that they can describe the relationship more 
accurately. In the future, we will further employ urban panel data for empirical analysis.

\section{Acknowledgments}

We acknowledge the financial support from the National Natural Science Foundation of China (Nos. 71373153, 71573217, and 71773075), the Major Projects of the National Social Science Foundation of Research on Supply-side Structural Reform and New Developing Impetus (No. 16ZDA006), the National Social Science Foundation of Research on Energy Consumption and Efficiency in New Urbanization Process (No. 15BTJ021), the Education and Scientific Research Project supported by the Education Department of Fujian Province (No. JAS170004), and Humanity and Social Science Youth Foundation of the Ministry of Education in China on "The Effects and Mechanism of Producer Services Cluster on Carbon Emissions Efficiency of Manufacturing in China" (Grant No. 18YJC790103)

\section{References}

Auty, R., Warhurst, A., 1993. Sustainable development in mineral exporting economies. Resour. Policy. https://doi.org/10.1016/0301-4207(93)90049-S

Baldwin, J.S., Allen, P.M., Winder, B., Ridgway, K., 2005. Modelling manufacturing evolution: Thoughts on sustainable industrial development. J. Clean. Prod. 13, 887-902. https://doi.org/10.1016/j.jclepro.2004.04.009

Bithas, K., Kalimetris, P., 2016. Revisiting the Energy-Development Link Evidence from the 20th Century for Knowledge-based and Developing Economies. Springer Book.

Bongaarts, J., 1992. Population Growth and Global Warming. Popul. Dev. Rev. 18, 299. https://doi.org/10.2307/1973681

Chang, N., 2015. Changing industrial structure to reduce carbon dioxide emissions: A Chinese application. J. Clean. Prod. 103, 40-48. https://doi.org/10.1016/j.jclepro.2014.03.003

Chenery, H., Srinivasan, T., 1989. Handbook of Development Economics. NorthHolland.

Ehrlich, Paul R; Holdren, J.P., 1971. Impact of Population Growth. Science (80-. ). 171, 1212-1217. https://doi.org/10.1002/9780470114735.hawley00624

$\mathrm{Fu}, \mathrm{Y} ., \mathrm{Ye}, \mathrm{X}$., W.Z., 2016. Structure changes in manufacturing industry and efficiency improvement in economic growth. Econ. Res. J. 8, 86-100. https://doi.org/10.19581/j.cnki.ciejournal.2014.09.006

Fu, Y., Ye, X., Wang, Z., 2016. Structure changes in manufacturing industry and efficiency improvement in economic growth. Econ. Res. J. 8, 86-100.

Gan, C., Zheng, R., Yu, D., 2011. An Empirical Study on the Effects of Industrial Structure on Economic Growth and Fluctuations in China. Econ. Res. J. 53, 4-16. 
Gylfason, T., Zoega, G., 2006. Natural resources and economic growth: The role of investment. World Econ. 29, 1091-1115. https://doi.org/10.1111/j.14679701.2006.00807.x

Hansen, B.E., 1999. Threshold effects in non-dynamic panels: Estimation, testing, and inference. J. Econom. 93, 345-368. https://doi.org/10.1016/S03044076(99)00025-1

Li, K., Lin, B., 2017. Economic growth model, structural transformation, and green productivity in China. Appl. Energy 187, 489-500. https://doi.org/10.1016/j.apenergy.2016.11.075

Liddle, B., 2013. Urban density and climate change: A STIRPAT analysis using city-level data. J. Transp. Geogr. 28, 22-29. https://doi.org/10.1016/j.jtrangeo.2012.10.010

Lin, B., Jiang, Z., 2009. Forecast of China's Environmental Kuznets Curve for $\mathrm{CO} 2$ emission and factors affecting China's $\mathrm{CO} 2$ emission. Manage. World 4, 27-36.

Liu, Y., Xie, Y., 2013. Asymmetric adjustment of the dynamic relationship between energy intensity and urbanization in China. Energy Econ. 36, 43-54. https://doi.org/10.1016/j.eneco.2012.12.003

Ma, Y., Cheng, D., 2017. "Resoure Gospel" or "Resource Curse"? on panel threshold model. Financ. Trade Res. 1, 13-25. https://doi.org/10.19337/j.cnki.341093/f.2017.01.002

Martínez-Zarzoso, I., Bengochea-Morancho, A., Morales-Lage, R., 2007. The impact of population on $\mathrm{CO} 2$ emissions: Evidence from European countries. Environ. Resour. Econ. 38, 497-512. https://doi.org/10.1007/s10640-007-9096-5

Martínez-Zarzoso, I., Maruotti, A., 2011. The impact of urbanization on CO2 emissions: Evidence from developing countries. Ecol. Econ. 70, 1344-1353. https://doi.org/10.1016/j.ecolecon.2011.02.009

Mi, Z.-F., Pan, S.-Y., Yu, H., Wei, Y.-M., 2015. Potential impacts of industrial structure on energy consumption and $\mathrm{CO} 2$ emission: a case study of Beijing. J. Clean. Prod. 103, 455-462. https://doi.org/10.1016/j.jclepro.2014.06.011

Mundaca, L., Markandya, A., 2016. Assessing regional progress towards a 'Green Energy Economy.' Appl. Energy 179, 1372-1394. https://doi.org/10.1016/j.apenergy.2015.10.098

Poumanyvong, P., Kaneko, S., 2010. Does urbanization lead to less energy use and lower $\mathrm{CO} 2$ emissions? A cross-country analysis. Ecol. Econ. 70, 434-444. https://doi.org/10.1016/j.ecolecon.2010.09.029

Shao, S., Yang, L., 2014. Natural resource dependence, human capital accumulation, and economic growth: A combined explanation for the resource curse and the resource blessing. Energy Policy 74, 632-642. https://doi.org/10.1016/j.enpol.2014.07.007

Sharma, S.S., 2011. Determinants of carbon dioxide emissions: Empirical evidence from 69 countries. Appl. Energy 88, 376-382. https://doi.org/10.1016/j.apenergy.2010.07.022

Sun, C., Luo, Y., Li, J., 2018. Urban traffic infrastructure investment and air pollution: Evidence from the 83 cities in China. J. Clean. Prod. 172, 488-496. https://doi.org/10.1016/j.jclepro.2017.10.194 
Sun, Y., Ye, C., 2012. Abundant Natural Resources and Industry Structure Distortion:Influence Mechanism and Multi-dimensional Measure. Soc. Sci. Nanjing 6, 1-8. https://doi.org/10.15937/j.cnki.issn1001-8263.2012.06.014

York, R., Rosa, E.A., Dietz, T., 2003. STIRPAT, IPAT and ImPACT: Analytic tools for unpacking the driving forces of environmental impacts. Ecol. Econ. 46, 351-365. https://doi.org/10.1016/S0921-8009(03)00188-5

Zhang, C., Lin, Y., 2012. Panel estimation for urbanization, energy consumption and CO2 emissions: A regional analysis in China. Energy Policy 49, 488-498. https://doi.org/10.1016/j.enpol.2012.06.048

Zhou, X., Zhang, J., Li, J., 2013. Industrial structural transformation and carbon dioxide emissions in China. Energy Policy 57, 43-51. https://doi.org/10.1016/j.enpol.2012.07.017 